D. Krüger, P. Oßwald, M. Köhler, P. Hemberger, T. Bierkandt, T. Kasper, The fate of the $\mathrm{OH}$ radical in molecular beam sampling experiments, Proceedings of the Combustion Institute 37 (2019) 1563-1570.

The original publication is available at www.elsevier.com

https://doi.org/10.1016/j.proci.2018.05.041

(C) 2018 This manuscript version is made available under the CC-BY-NC-ND 4.0 license http://creativecommons.org/licenses/by-nc-nd/4.0/ 


\section{The fate of the $\mathrm{OH}$ radical in molecular beam sampling experiments}

Dominik Krüger ${ }^{1 *}$, Patrick Oßwald ${ }^{1}$, Markus Köhler ${ }^{1}$, Patrick Hemberger ${ }^{2}$, Thomas Bierkandt ${ }^{3,1}$ and Tina Kasper $^{3}$

${ }^{1}$ Institute of Combustion Technology, German Aerospace Center (DLR), 70569 Stuttgart, Germany

${ }^{2}$ Laboratory for Femtochemistry and Synchrotron Radiation, Paul Scherrer Institute, CH-5232 Villigen, Switzerland

${ }^{3}$ Mass Spectrometry in Reactive Flows - Thermodynamics (IVG), University of Duisburg-Essen,

47057 Duisburg, Germany

*Corresponding Author: Dominik Krüger, German Aerospace Center (DLR), Pfaffenwaldring 38-40, 70569 Stuttgart, Germany

phone: $+497116862-656$

email: dominik.krueger@dlr.de

\section{Colloquium Topic Area: Laminar flames}

Word counts (method 1)

\begin{tabular}{|l|l|l|}
\hline Part & Method & \# words \\
\hline Abstract & Microsoft Word 2010 word count & 280 \\
\hline Main text & Microsoft Word 2010 word count & 3624 \\
\hline Equations & $(5)$ lines $\times 7.6$ words/line & 38 \\
\hline References & $(40+2) \times 2.3$ lines $/$ ref $\times 7.6$ words/line & 734 \\
\hline Tables & {$[(9+2) \times 7.6$ words/line $]+9$} & 92 \\
\hline Figure 1 & {$[(43 \mathrm{~mm}+10 \mathrm{~mm}) \times 2.2$ words $/ \mathrm{mm} \times 1]+15$} & 132 \\
\hline Figure 2 & {$[(63 \mathrm{~mm}+10 \mathrm{~mm}) \times 2.2$ words $/ \mathrm{mm} \times 1]+17$} & 178 \\
\hline Figure 3 & {$[(55 \mathrm{~mm}+10 \mathrm{~mm}) \times 2.2$ words $/ \mathrm{mm} \times 1]+47$} & 204 \\
\hline Figure 4 & {$[(67 \mathrm{~mm}+10 \mathrm{~mm}) \times 2.2$ words $/ \mathrm{mm} \times 2]+46$} & 385 \\
\hline Figure 5 & {$[(72 \mathrm{~mm}+10 \mathrm{~mm}) \times 2.2$ words $/ \mathrm{mm} \times 2]+36$} & 397 \\
\hline Figure 6 & {$[(55 \mathrm{~mm}+10 \mathrm{~mm}) \times 2.2$ words $/ \mathrm{mm} \times 1]+31$} & 174 \\
\hline Figure 7 & {$[(55 \mathrm{~mm}+10 \mathrm{~mm}) \times 2.2$ words $/ \mathrm{mm} \times 1]+15$} & 158 \\
\hline Total $($ excl. abstract $)$ & & $\mathbf{6 1 1 6}$ \\
\hline Maximum Count & & 6200 \\
\hline & & \\
\hline
\end{tabular}

Submitted to the $37^{\text {th }}$ International Symposium on Combustion, Dublin, 2018

Color figures in electronic version only. 


\section{Abstract}

The collisional history of ionized molecules in a molecular beam mass spectrometric flame experiment is target of our present investigation. Measurements in a double imaging photoelectron photoion coincidence spectroscopy (i ${ }^{2}$ PEPICO) were performed at the Swiss Light Source (SLS) of the Paul Scherrer Institute to use the ion imaging device for separating the molecular beam ions from rethermalized ions. This enables the precise composition study of the individual types of ions. Results show clearly for the $\mathrm{OH}$ radical that the complete signal is obtained from the molecular beam, while the signal from other combustion compounds features additional rethermalized molecules. As for $\mathrm{OH}$ radicals, the mole fraction is reduced by sampling effects and contact with the ionization vessel walls significantly. Consequently, this leads to signal loss and lower mole fractions, when using ionization cross sections for the quantification. To improve on this, a beam fraction (BF) factor is presented. The factor describes the ratio of the separated beam signal without rethermalized ions with the total ion signal, consisting of the mass to charge ratio from the molecular beam and additional rethermalized ions. Since the detected $\mathrm{OH}$ radicals are solely from the molecular beam, a new method of comparing two molecular beam alignments using the $\mathrm{OH}$ to $\mathrm{H}_{2} \mathrm{O}$ signal ratio is presented. This method has a decent potential for the optimization of the quality of molecular beams. Finally, the separated beam signal (without the rethermalized ions) was used to determine mole fraction profiles for the $\mathrm{OH}$ radical using ionization cross sections. These profiles are in good agreement with model predictions of the USC-II and the Aramco Mech 2.0 mechanisms, while the total signal leads to factor of 12 smaller $\mathrm{OH}$ mole fractions. 
Keywords: $\mathrm{OH}$ mole fractions, laminar premixed flame, $i^{2} \mathrm{PEPICO}$, molecular beam, ion velocity imaging

\section{Introduction}

Elemental reactions in combustion systems are known to be mostly driven by small radicals like $\mathrm{H}$, $\mathrm{O}$ and $\mathrm{OH}$. For example, the abstraction of $\mathrm{H}$ atoms from hydrocarbons or the direct addition of $\mathrm{OH}$ radicals are known reaction types in the combustion chemistry [1], which are well implemented in kinetic reaction mechanisms [2,3]. For an adequate analysis of these reactions, precise detection and quantification of the reaction products as well as the small radicals themselves are indispensable. Molecular beam mass spectrometry (MBMS) typically enables the detection of various stable and reactive species and it is a widely used method for validating kinetic mechanisms [4-6].

Even though convincing species profiles have been reported in the early days of MBMS flame sampling experiments [7], these results often rely on extensive data processing. In particular, measurements performed by electron impact ionization almost always require a proper fragmentation correction. In modern synchrotron based single photon ionization experiments, almost fragmentation free measurements are possible, while the detection of small radicals and the subsequent quantification has proven to be highly challenging $[5,8]$. One main reason for these challenges is that the probe used for sampling from the reactive environment severely perturbs the flame and distorts the flame structure. Biordi et al. described a thermal perturbation due to a cooling effect of the inserted probes and recommended the use of probe materials with low thermal conductivity [9]. Knuth et al. summarized different effects like chemical relaxation in the free jet and radical recombination at probe surfaces [10]. A signal shift up to higher burner probe distances induced by an acceleration of gas molecules into the probe orifice was observed by several authors [11-13]. Recently, simulations of probe sampling by computational fluid dynamics codes and X-ray fluorescence measurements have helped to visualize and quantify the perturbation effects for selected flame conditions [14-16]. In addition, chemical relaxation, which is mainly based on a 
reaction between $\mathrm{OH}$ and $\mathrm{H}_{2}$ during the expansion in the free jet $[10,11]$, affects the $\mathrm{OH}$ mole fraction.

Radical recombination reactions at the probe surface is responsible for the reduction of $\mathrm{OH}$ radicals by reaction with other intermediates such as $\mathrm{OH}, \mathrm{H}$ and $\mathrm{O}[10]$. Most of the discussed effects are highly dependent on the particular sampling and flame conditions of the individual experiment. To overcome the challenges of reduced $\mathrm{OH}, \mathrm{O}$ and $\mathrm{H}$ radical concentrations, quantification is typically carried out by using a partial equilibration of $\mathrm{H}_{2} / \mathrm{O}_{2}$-reactions $[11,17-22]$, while most of the other species are evaluated using measured ionization cross sections. The reactions involved these equilibria ((1), (2)) and the equation (3) used for the calculation of the exhaust gas values for the $\mathrm{OH}$ mole fraction are given below.

(1) $K_{1}[\mathrm{H}]\left[\mathrm{O}_{2}\right]=[\mathrm{OH}][\mathrm{O}]$

(2) $K_{2}[\mathrm{O}]\left[\mathrm{H}_{2}\right]=[\mathrm{OH}][\mathrm{H}]$

(3) $[\mathrm{OH}]=\left(K_{1} K_{2}\left[\mathrm{O}_{2}\right]\left[\mathrm{H}_{2}\right]\right)^{\frac{1}{2}}$

$K_{1}$ and $K_{2}$ are equilibrium constants for the reaction (1) and (2) and can be derived from thermodynamic data and the exhaust gas temperature. The partial equilibration method is consequently strongly dependent on the exhaust gas temperature as well as the $\mathrm{H}_{2}$ and the $\mathrm{O}_{2}$ exhaust gas mole fractions. In addition to the partial equilibration, radical profiles obtained by probe sampling can be matched to mole fraction measured by other methods. This procedure is known in literature, but the data is sparse. Stepowski et al. normalized their $\mathrm{OH}$ profile to their LIF measurements [13], while Cool et al used the model prediction for the normalization [23]. Knyazkov et al. showed some $\mathrm{H}$ - and $\mathrm{OH}$ profiles in counterflow diffusion flames, but did not describe the calibration method for this species in detail [24]. The group of Korobeinichev presented measurements of $\mathrm{OH}$ radicals in atmospheric and high pressure systems calibrated by using ionization cross sections [25-27] estimated by the relative ionization cross section method (RICS), 
which is based on measurements of electron ionization efficiency curves of chemically similar species $[7,9]$.

In the present work, double imaging photoelectron photoion coincidence spectroscopy $\left(\mathrm{i}^{2} \mathrm{PEPICO}\right)$ is used to examine downstream effects occurring after formation of the molecular beam used for sampling from a flame environment [28]. This setup has previously turned out to be an adequate tool for the investigation of different stable and reactive intermediates, especially for the determination of mole fraction profiles of radicals in flame environments [28-30] or understanding catalytic fast pyrolysis on a molecular level [31]. Thanks to the ion velocity map imaging (VMI) technique used in this study, the signal originating from the molecular beam can be separated from the rethermalized background, which occurs after the gas jet collides with the ionization vessel walls and diffuses into the ionization volume. Here we measure $\mathrm{OH}$ radical concentrations directly using photoionization cross sections.

\section{Experimental}

The experiments were performed at the $i^{2}$ PEPICO endstation at the VUV-beamline at the Swiss Light Source (SLS) of the Paul Scherrer institute. Detailed information on iPEPICO [28, 30] and $i^{2}$ PEPICO [32-34] and their application for flame analysis are given in the literature. In brief, a premixed flame stabilized on a McKenna-type flat-flame burner was sampled by a nozzle $(0.32 \mathrm{~mm}$ orifice). Rapid expansion of the gas sample into high vacuum forms a molecular beam, which, guided through the skimmer (2.0 mm orifice), points into the ionization volume of the spectrometer. The nozzle skimmer distance was $60 \mathrm{~mm}$. The pressure for the first and second pumping stage was near $10^{-5}$ mbar and $10^{-6}$ mbar. The pressure in the burner chamber was set to 40 mbar. Under these conditions no well-developed supersonic expansion can be expected and cooling of the rotational temperatures of the flame sampled gases is achieved to only $300-500 \mathrm{~K}$ [35].

The sampled molecules are ionized by VUV-synchrotron radiation in the range of 60-250 nm (5-21 $\mathrm{eV})$. The ejected electrons are extracted by an electric field, they enter a field-free drift region and 
are detected by a velocity map imaging (delay line anode) detector. The coincident ions are also detected by velocity map imaging (VMI), while also good mass resolution can be achieved due to Wiley McLaren space focusing conditions. The upgrade of the SLS instrument to $i^{2}$ PEPICO detection was instrumental to the experiments presented here, and details on the actual instrumentation may be found in [33]. Using VMI detection for the ions permits visualization of the initial velocities of the neutral molecules before the ionization process. The working principle is shown in Fig.1.

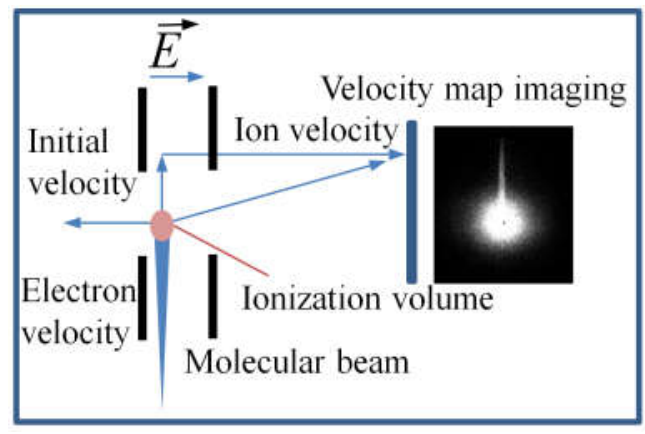

Figure 1. Concept of the visualization of the molecular beam using the velocity map image.

Due to the acceleration of ions towards the detectors from a fixed ionization volume, the position of impact depends on both the initial velocity of the neutral molecule as well as on its molecular weight. Upon expansion into the high vacuum a molecular beam is formed, which shows a high velocity component in the gas expansion direction (see Figure 2). This leads to two components in the images. A broad spot in the center of the image can be assigned to ionized species with a room temperature velocity distribution, while the molecular beam component is mostly imaged as narrow speed distribution (marked in red). Using this spatial separation enables the selection of molecular beam components upon data analysis excluding the rethermalized ones. This cannot be achieved in typical ToF-MBMS-setups.

For the present investigation, laminar low pressure (40 mbar) premixed hydrogen flames (1000 sccm Ar, $1200 \mathrm{sccm} \mathrm{O}_{2}$ and $1600-1800 \mathrm{sccm} \mathrm{H}_{2}$ dependent on the C-H-ratio) doped with ethane (200 
sccm), $n$-butane, $i$-butane and 1-butene $(100 \mathrm{sccm})$ at a stoichiometry of $\Phi=1.25$ are used. The flames have been described in [30] and are designed to exhibit similar $\mathrm{OH}$ concentrations.

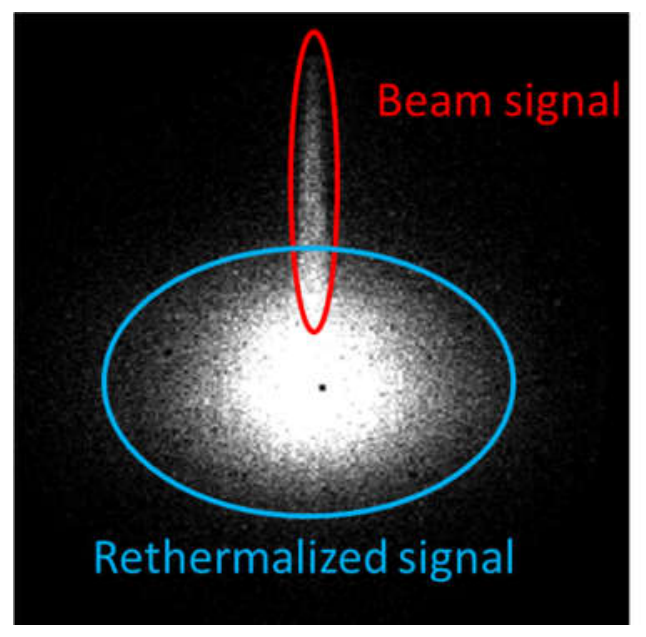

Figure 2. Velocity map image of a molecular beam setup with marked beam signal and rethermalized signal.

The quantification of the experimental $\mathrm{OH}$ mole fractions was herein performed using photoionization cross sections from the photoionization cross section database (Version 2.0) of the Synchrotron Radiation Laboratory in Hefei [36] based on the measurements from Dehmer [37]. This quantification was performed for the restricted molecular beam signal as well as for the overall signal as described below. Major species profiles are calculated by an internal calibration procedure shown by Oßwald et al. [28] to determine the mole fraction of $\mathrm{Ar}$ and $\mathrm{H}_{2} \mathrm{O}$. The $\mathrm{OH}$ mole fractions are calculated according to Equation (4). $\mathrm{x}_{\mathrm{Ar}}$ and $\mathrm{x}_{\mathrm{OH}}$ are the mole fractions of Argon and $\mathrm{OH}, \mathrm{S}_{\mathrm{Ar}}$ and $\mathrm{S}_{\mathrm{OH}}$ the respective integrated signals at the photon energy $\mathrm{E}$ (either total signal or restricted to the molecular beam circled in red in Fig. 2) and $\sigma_{\mathrm{Ar}}$ and $\sigma_{\mathrm{OH}}$ the photoionization cross sections for Ar and $\mathrm{OH}$ at the selected photon energy. The energy dependent scan factor $(\mathrm{c}(\mathrm{E}))$, which is used to compensate systematic changes of the system response at selected energy, can be determined by using equation (4) and changing the $\mathrm{OH}$ to a molecule with known mole fractions (e.g. $\mathrm{H}_{2} \mathrm{O}$ known from the major species profiles). 


$$
\text { (4) } \frac{\mathrm{x}_{\mathrm{OH}}}{\mathrm{x}_{\mathrm{Ar}}}=\frac{\mathrm{S}_{\mathrm{OH}}(\mathrm{E})}{\mathrm{S}_{\mathrm{Ar}}(16 \mathrm{eV})} \cdot \frac{\sigma_{\mathrm{Ar}}(16 \mathrm{eV})}{\sigma_{\mathrm{OH}}(\mathrm{E})} \cdot \frac{1}{\mathrm{c}(\mathrm{E})}
$$

$\mathrm{OH}$ signal was simulated using the burner-stabilized Cantera flame reactor module of the Chemical Workbench of Kintech Lab Ltd. [38] with the USC II mechanism [2] and the Aramco Mech 2.0 [3] two well validated $\mathrm{H}_{2} / \mathrm{C}_{1}-\mathrm{C}_{4}$ combustion mechanisms.

\section{Results and Discussion}

The hydrocarbon doped hydrogen flames were investigated with the CRF-PEPICO spectrometer with a focus on the $\mathrm{OH}$ signal. Figure 3 shows the $\mathrm{OH}$ mole fraction profile obtained by using the signal of molecular beam and rethermalized ions (overall signal) and the direct quantification method (Eq. 4) without partial equilibrium assumptions compared to a simulated $\mathrm{OH}$ mole fraction profile using the USC II Mechanism [2] and the mole fraction profile calculated with the partial equilibration method. The temperature profile used for the simulations is shown too. While the model predicts a maximum $\mathrm{OH}$ mole fraction of $1.2 \%$, the experimental data result in an order of magnitude smaller mole fraction with literature ionization cross sections.

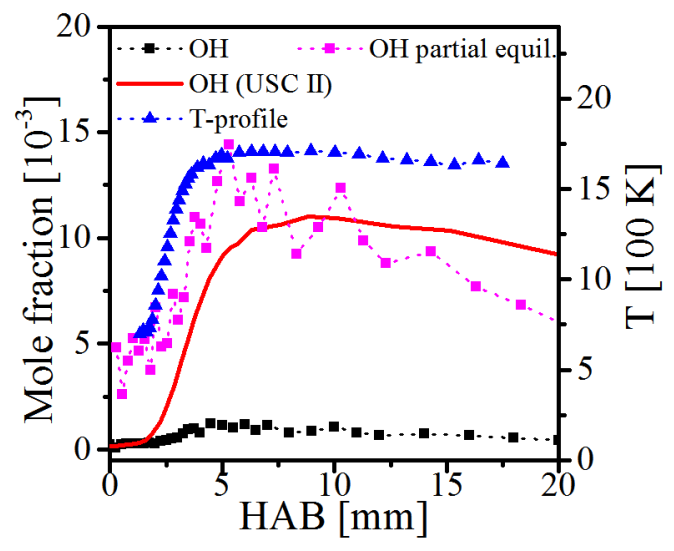

Figure 3. Comparison between experimental $\mathrm{OH}$ mole fraction using the overall signal and ionization cross sections for the quantification, the experimental mole fraction using the partial equilibration and the USC II model predictions [2] in a butene doped $\mathrm{H}_{2}$ flame. The temperature profile is presented in blue. 
The exhaust gas mole fraction of the $\mathrm{OH}$ radical calculated by the partial equilibration method outline above for this flame is $0.6 \%$ and, consequently, matches better with the simulations than the quantification with ionization cross sections. The difference between our experimental data on the one hand and the model prediction as well as the exhaust gas mole fraction from the partial equilibration on the other hand suggests that the $\mathrm{OH}$ mole fractions are approximately $90 \%$ to small.

Several reasons can be found to interpret this finding. First, the sampling nozzle is likely to cause effects like a thermal perturbation [9], having an impact on the $\mathrm{OH}$ signal by lowering the temperature in the sampling region. This effect has been included in our simulations by using perturbed temperature profiles as described in the literature [30,39] and consequently cannot explain the $\mathrm{OH}$ signal loss. Reactions on the nozzle surface [10] can induce an abreaction of the very reactive $\mathrm{OH}$ radicals. Second, rethermalized species (i.e. molecules, which have collided with the walls of the vacuum vessel) are still present and dominate the ion signal in our molecular beam setup as shown in Fig.1. For example, in our experiment only $10 \%$ of the total ion signal contributes to the red marked accelerated ions and can be assigned to the beam signal. The molecular composition of the rethermalized species can be different from the composition of the molecular beam species. Reactive intermediates can perform some surface reactions, when hitting the vacuum vessels walls, while more stable compounds can diffuse back into the ionization volume after colliding with the walls of the spectrometer chamber. Third, gas-type dependent pumping speeds of the turbo molecular pumps [40] can change the composition of the residual gas in the chamber and affect the mole fractions of the rethermalized molecules. These effects can lead to a change in the detected signal fractions between the compounds and consequently lead to mole fractions that differ from the sampled gas composition.

To explore the impact of the signal contribution of the rethermalized and the molecular beam species, the overall ion signal as well as the molecular beam ion signal is integrated and compared. This treatment can show, how the relative abundance of specific molecules in the molecular beam deviates from the relative abundance in the rethermalized gas. 
In the following, the signal ratios of ion signal of species in the beam and in the residual gas, called beam fraction, are compared for a radical species $(\mathrm{OH})$ and a stable species $\left(\mathrm{H}_{2} \mathrm{O}\right)$. Figure 4 (left) compares the total ion signal of the $\mathrm{OH}$ radical and its signal in the molecular beam. On the right side, the comparison is repeated for water. Both signals were obtained from the same scan in a 1-butene doped hydrogen flame at $13.56 \mathrm{eV}$. This ensures that both species are measured at the same conditions and negates effects like differences in beam intensities. It is obvious that both signals decrease when focusing only on the beam signal. The fraction between beam signal and overall signal is larger than for the $\mathrm{H}_{2} \mathrm{O}$ signal. The amount of water permanently found in the ionization vessel, is below $20 \%$ for this measurement and cannot be accounted for the differences in the fractions. The high beam fractions indicates, that $\mathrm{OH}$ is primarily present in the molecular beam and not in the wall-scattered rethermalized signal, while water is present in both parts of the image. The beam fraction $(\mathrm{BF})$ seems to be an adequate parameter for the signal distribution between beam signal and rethermalized signal. The BFs are derived using equation (5). Max $(i)_{\text {beam }}$ and $\operatorname{Max}(i)_{\text {overall }}$ are the maximum signal values in a HAB scan integrated over the beam signal or the overall signal.

$$
B F(i)=\frac{\operatorname{Max}(i)_{\text {beam }}}{\operatorname{Max}(i)_{\text {overall }}}
$$



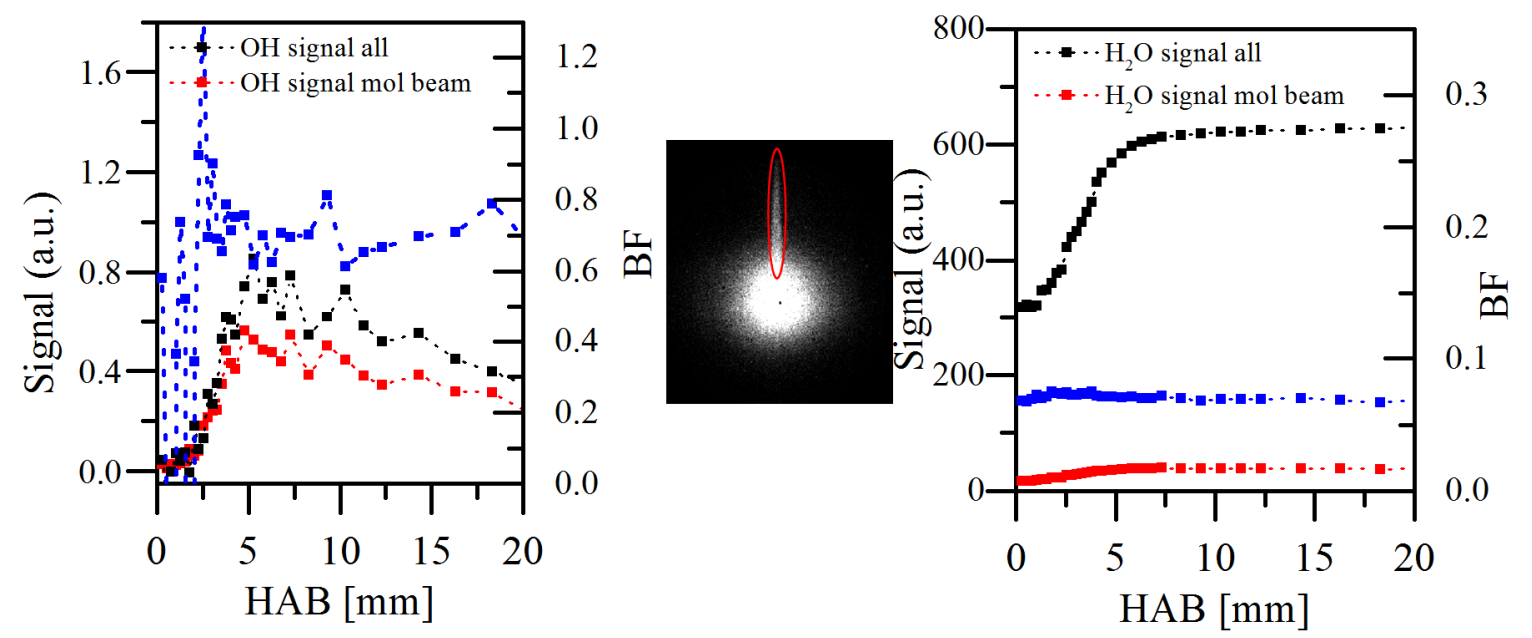

Figure 4. Comparison of $\mathrm{OH}$ and $\mathrm{H}_{2} \mathrm{O}$ signal with focus on the molecular beam area (red) and the overall signal as well as the related BFs. For the illustration of the molecular beam a velocity map image is shown with molecular beam area marked in red.

This $\mathrm{BF}$ for $\mathrm{OH}$ in the molecular beam is significantly higher than for other observed radicals like $\mathrm{CH}_{3}, \mathrm{H}$ and $\mathrm{C}_{2} \mathrm{H}_{5} / \mathrm{HCO}$ on $\mathrm{m} / \mathrm{z}=29$. In this extent, this is an exclusive phenomenon of the $\mathrm{OH}$ radicals. Figure 5 (left side) shows the normalized signal for different small radicals for the 1-butene doped hydrogen flame. The profiles are normalized to the maximum of the overall signal peaks. On the right side, the BFs are shown for these species. All BFs are on the same order of magnitude (around $5 \%$ ) except for the $\mathrm{OH}$ signal and are nearly stable over the HAB range where a reasonable signal could be detected. Based on this observation, it can be concluded that $\mathrm{OH}$ radicals go through fewer collisions compared to other radicals. 


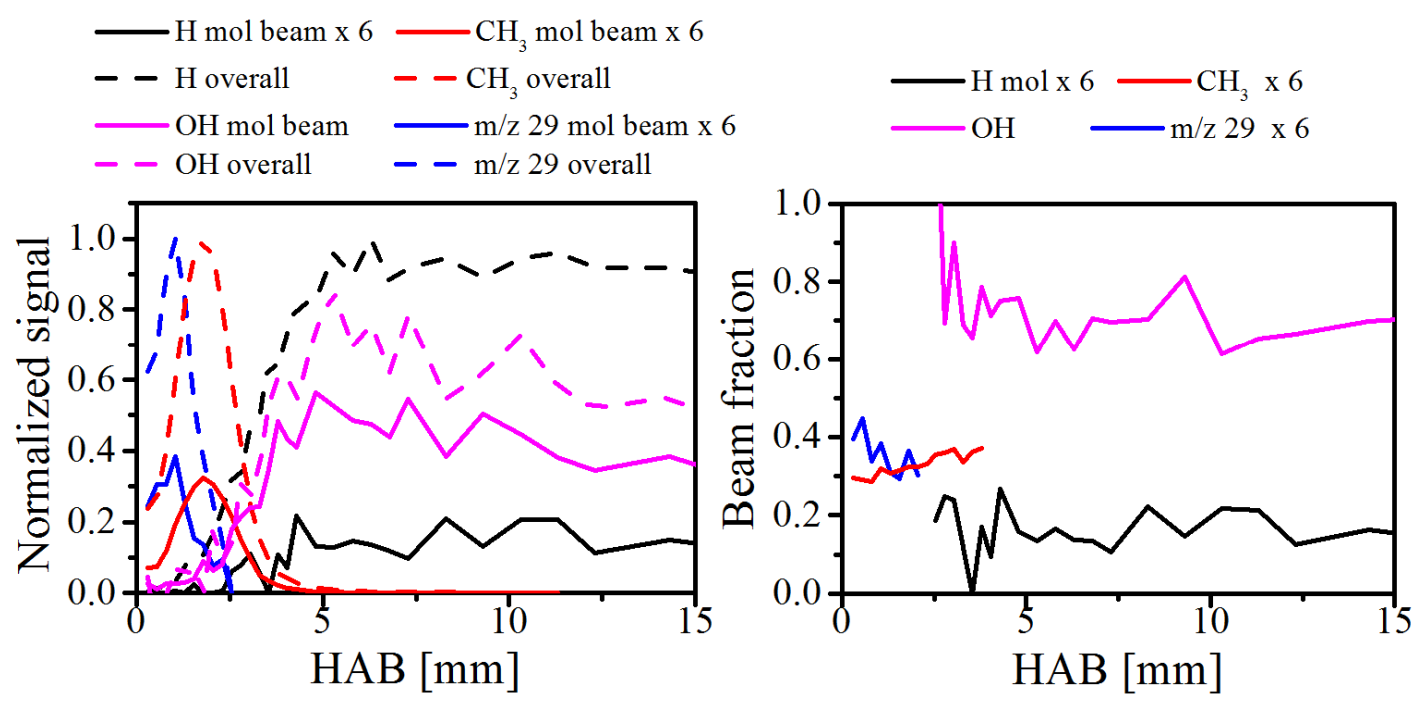

Figure 5. Overall and beam signal profiles of different radicals (left) normalized to the maximum of the overall signal of the appropriate radical in the 1-butene doped flame and the beam fractions (right) for the same species.

We have determined the beam fractions at the maximum signal in four different doped hydrogen flames for $\mathrm{OH}, \mathrm{H}, \mathrm{Ar}, \mathrm{H}_{2} \mathrm{O}$. For the 1-butene doped flame additional beam fractions for $\mathrm{CH}_{3}$ and $\mathrm{C}_{2} \mathrm{H}_{5}$ were determined. Unfortunately measurements with the respective photon energies $(8.47 \mathrm{eV}$ and $10.02 \mathrm{eV}$ ) were only performed in the 1-butene flame with the $i^{2}$ PEPICO setup. For the other fuels, only measurements at higher photon energies were performed $(13.65 \mathrm{eV}, 14.35 \mathrm{eV}$ and 16.2 $\mathrm{eV}$ ) because the focus is on the $\mathrm{OH}$ signal. Consequently, the number of other species shown here is limited compared to other mass spectrometric works. Table 1 summarizes the beam fractions of different species $i$.

Table 1 Beam fractions for different species indifferent flames.

\begin{tabular}{|l|l|l|l|l|}
\hline $\mathrm{BF}$ & $\mathrm{C}_{2} \mathrm{H}_{6}$ & $n-\mathrm{C}_{4} \mathrm{H}_{10}$ & $i-\mathrm{C}_{4} \mathrm{H}_{10}$ & $1-\mathrm{C}_{4} \mathrm{H}_{8}$ \\
\hline $\mathrm{OH}$ & $67 \%$ & $66 \%$ & $65 \%$ & $65 \%$ \\
\hline $\mathrm{Ar}$ & $5.6 \%$ & $5.5 \%$ & $5.5 \%$ & $5.4 \%$ \\
\hline $\mathrm{H}_{2} \mathrm{O}$ & $6.1 \%$ & $6.3 \%$ & $6.3 \%$ & $6.2 \%$ \\
\hline $\mathrm{H}$ & $3.6 \%$ & $4.0 \%$ & & $3.6 \%$ \\
\hline $\mathrm{CH}_{3}$ & & & & $5.4 \%$ \\
\hline $\mathrm{C}_{2} \mathrm{H}_{5}$ & & & & $6.4 \%$ \\
\hline $\mathrm{CH}_{4}$ & $5.5 \%$ & $5.6 \%$ & $5.4 \%$ & $5.0 \%$ \\
\hline
\end{tabular}




\begin{tabular}{|l|l|l|l|l|}
\hline $\mathrm{C}_{2} \mathrm{H}_{6}$ & $7.1 \%$ & $4.0 \%$ & $4.5 \%$ & $4.1 \%$ \\
\hline
\end{tabular}

BFs of $\mathrm{OH}$ are in the range of $65 \%$ to $67 \%$ and well comparable. The BFs for Ar (around $5.5 \%$ ) and water (around $6 \%$ ) and the hydrogen radical (around $4 \%$ ) are an order of magnitude smaller for all flames and agree well for the same species in different flames. The same is true for other stable species like $\mathrm{CH}_{4}$ and $\mathrm{C}_{2} \mathrm{H}_{6}$ with $\mathrm{BFs}$ around 4-7 \%. The experimental data shows good reproducibility and the BFs are independent from the doped fuel. Since all flames had very similar flow rates and pressures, the dependence of the BF on the sampling conditions was not tested in the experiments presented here. For the hydrogen radical in the $i$-butane doped flame no reasonable value for the $\mathrm{BF}$ could be determined, caused by a bad signal-to-noise ratio of the $\mathrm{H}$ atom signal. The beam fractions of the hydrogen radical in the other flames are clearly smaller than those of water and argon. The light $\mathrm{H}$ atoms have the largest dispersion in the molecular beam and it is possible that some ion signals are outside of the selected beam area. This effect leads to mass discrimination in other instruments and suggests a mass discrimination of $50 \%$, when the signals of argon and $\mathrm{H}$ atoms are compared.

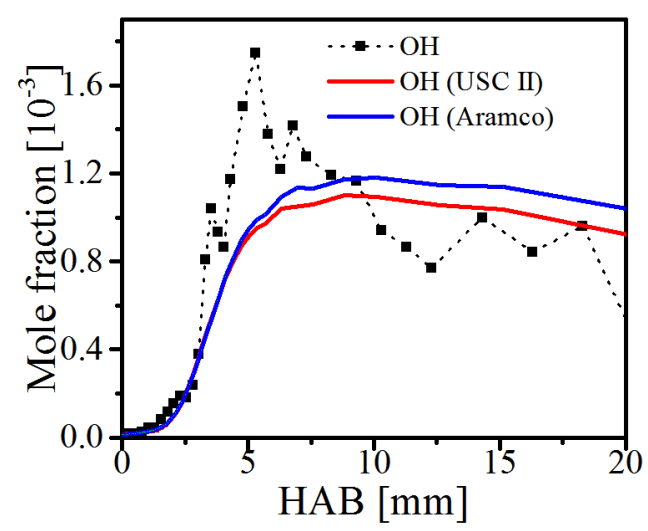

Figure 6. Mole fraction profile of the $\mathrm{OH}$ radical using the beam signal for the quantification compared to the model predictions with the USC II [2] and the Aramco Mech 2.0 [3].

The fact that $\mathrm{OH}$ radicals exist in significantly lower quantities outside of the molecular beam than other species, leads to lower mole fractions in the experimental data, when the ion signal from the molecular beam and the residual gas cannot be discriminated and ionization cross sections and 
signals ratios are used for the quantification (Fig. 2). The relative amount of $\mathrm{OH}$ present in the molecular beam is found to be 12 times higher than in the overall signal in all flames. The nature of the reactions taking place cannot be decided based on the experiments presented in this work, but it is not unlikely that surface reactions, e.g. with the thin water film on the chamber walls, are involved. Also, reactions of the $\mathrm{OH}$ radicals in the chamber volume due to comparatively long residence times of the rethermalized molecules cannot be entirely excluded. The differences in pumping speed decrease typically strictly monotonously with increasing molecular weight and so different pumping efficiencies of water $(\mathrm{M}=18)$ and $\mathrm{OH}(\mathrm{m}=17)$ can be excluded as explanation of the observations on the BF [40]. Based on Franck-Condon factors for transitions from neutral $\mathrm{OH}$ to ionic $\mathrm{OH}$ and the population of the vibrational ground state and excited vibrational states at different flame-relevant temperatures, a higher ionization efficiency of the $\mathrm{OH}$ with larger vibrational temperature in the molecular beam can also be ruled out as sole explanation of the large $\mathrm{BF}$ of $\mathrm{OH}$.

By using the beam signal for the quantification instead of the overall signal, a mole fraction profile with significantly better agreement to the model predictions is obtained. Moreover, the exhaust gas values calculated by partial equilibration are matched equally better. This mole fraction profile for $\mathrm{OH}$ in the $n$-butane doped flame is shown as illustration in Fig. 6 and compared to two model predictions for the $\mathrm{OH}$ radicals. Both model predictions are in very good agreement with the experimental data. Compared to the quantification method via partial equilibration, this method has the advantage that no exhaust gas temperature is needed to calculate the correct $\mathrm{OH}$ mole fractions and the mole fractions are independent of inaccuracies in the $\mathrm{O}_{2}$ exhaust gas mole fraction. Figure 7 shows the $\mathrm{OH}$ mole fractions of all four flames quantified with this method compared to each other. The mole fraction profiles show that for all flames, the $\mathrm{OH}$ profiles are similar and the quantification delivers reproducible results. 


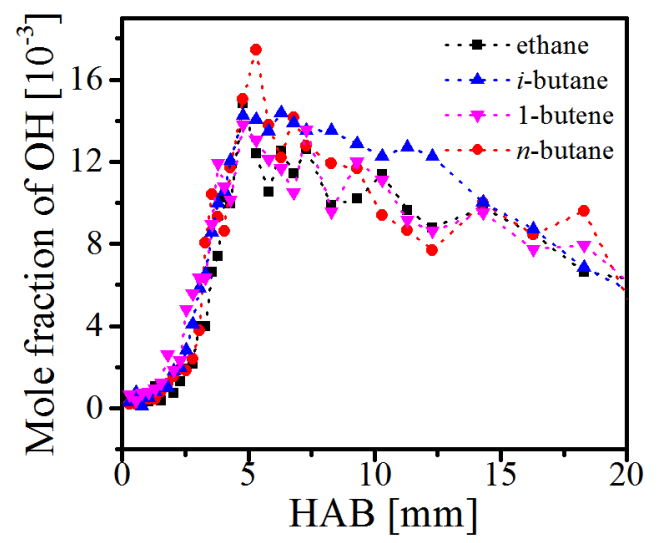

Figure 7. $\mathrm{OH}$ mole fraction profiles for all four fuel-doped flames compared to each other.

For flame chemistry studies by MBMS it is of crucial importance to measure ion signals in the molecular beam and not in the residual gases, where reactions can have occurred. The ion imaging properties of the $i^{2}$ PEPICO Spectrometer can be used to optimize the molecular beam by adjusting experimental parameters, e.g. pressure gradient, nozzle and skimmer orifice diameters and nozzleskimmer distance, for highest BF. These experimental design parameters are intended to help improvement of MBMS instruments without imaging capabilities. A systematic design study is very time-consuming because the vacuum needs to be broken for each optimization step and was not possible in these initial experiments reported here. However, based on the results presented here, an efficient test to check and improve MBMS systems without imaging detection is suggested. Therefore, a flame environment has to be set up and a good sampling position for $\mathrm{OH}$ is mandatory. The $\mathrm{OH}$ signal can be measured compared to a stable molecule (for example water) and the resulting $\mathrm{OH}$ to $\mathrm{H}_{2} \mathrm{O}$ ratio can be used to optimize the molecular beam setup. Molecular beam parameters should be varied until the highest ratio of $\mathrm{OH}$ to water signals is achieved. This method enables an assessment of the molecular beam setup without using an ion imaging setup.

\section{Conclusion}

Imaging PEPICO measurements were performed to evaluate the molecular beam signal by determining species mole fractions from the molecular beam and separating contributions from 
rethermalized species, e.g. from prior to detection wall-scattering. The molecular beam was separated from the rethermalized ions using the ion imaging feature of the CRF-PEPICO instruments at the SLS. We could show that the $\mathrm{OH}$ signal is exclusively present in the molecular beam. This effect is explained by reactions of the $\mathrm{OH}$ radicals hitting the walls of the vacuum vessel. Other molecules, including other radicals, do not suffer the same losses due to scattering. Regarding the overall signal the $\mathrm{OH}$ radical has a factor of 12 lower relative signal than argon in this experiment. A beam fraction was defined to compare the ion signal intensity in the molecular beam and in the residual gases of several species. Mole fractions are typically determined from signal ratios and photoionization cross sections with respect to a reference species with known mole fraction. Correct mole fractions of $\mathrm{OH}$ can be obtained from the MBMS experiment with this evaluation method, if only the signal in the molecular beam is considered. The separation of the molecular beam signal enables to improve the resulting mole fractions, especially for poor molecular beam alignments. The $\mathrm{OH}$ mole fraction values obtained in this way are in good agreement with kinetic model predictions and are in the same range as the values calculated with a partial equilibrium assumption. The work provides for the first time experimental evidence of the reasons for the often observed signal loss of $\mathrm{OH}$ radicals and points to optimization procedures, which can be performed for MBMS setups without imaging capabilities.

\section{Acknowledgements}

All experiments were carried out at the VUV beamline of the Swiss Light Source of the Paul Scherrer Institute and were financially supported by the Deutsche Forschungsgesellschaft (DFG) under contract KA3871/3-1 and KO4786/2-1, the Swiss Federal Office of Energy (SFOE) under contract SI/501269-01 and by the European Community's Seventh Framework Program (FP7/20072013) under grant agreement $n .^{\circ} 312284$ (CALIPSO). We thank Patrick Ascher (PSI) for technical support. 


\section{References}

[1] N. Hansen, T.A. Cool, P.R. Westmoreland, K. Kohse-Höinghaus, Prog. Energy Combust. Sci. 35 (2009) 168191.

[2] H. Wang, X. You, A.V. Joshi, S.G. Davis, A. Laskin, F. Egolfopoulos, C.K. Law, USC Mech Version II. HighTemperature Combustion Reaction Model of $\mathrm{H}_{2} / \mathrm{CO} / \mathrm{C} 1-\mathrm{C} 4$ Compounds. http://ignis.usc.edu/USC Mech II.htm, May 2007.

[3] Y. Li, C.-W. Zhou, K.P. Somers, K. Zhang, H.J. Curran, Proc. Combust. Inst. 36 (2017) 403-411.

[4] T.A. Cool, A. Mcllroy, F. Qi, P.R. Westmoreland, L. Poisson, D.S. Peterka, M. Ahmed, Rev. Sci. Instrum. 76 (2005) 094102.

[5] T.A. Cool, K. Nakajima, C.A. Taatjes, A. Mcllroy, P.R. Westmoreland, M.E. Law, A. Morel, Proc. Combust. Inst. 30 (2005) 1681-1688.

[6] N. Hansen, J.A. Miller, P.R. Westmoreland, T. Kasper, K. Kohse-Höinghaus, J. Wang, T.A. Cool, Combust. Flame 156 (2009) 2153-2164.

[7] C.P. Lazzara, J.C. Biordi, J.F. Papp, Combust. Flame 21 (1973) 371-382.

[8] Z. Zhou, X. Du, J. Yang, Y. Wang, C. Li, S. Wei, L. Du, Y. Li, F. Qi, Q. Wang, J. Synchrotron Rad. 23 (2016) 1035-1045.

[9] J.C. Biordi, Prog. Energy Combust. Sci. 3 (1977) 151-173.

[10] E.L. Knuth, Combust. Flame 103 (1995) 171-180.

[11] R.J. Cattolica, S. Yoon, E.L. Knuth, Combust. Sci. Technol. 28 (1982) 225-239.

[12] F.N. Egolfopoulos, N. Hansen, Y. Ju, K. Kohse-Höinghaus, C.K. Law, F. Qi, Prog. Energy Combust. Sci. 43 (2014) 36-67.

[13] D. Stepowski, D. Puechberty, M.J. Cottereau, Symp. Int. Combust. 18 (1981) 1567-1573.

[14] L. Deng, A. Kempf, O. Hasemann, O.P. Korobeinichev, I. Wlokas, Combust. Flame 162 (2015) 1737-1747.

[15] N. Hansen, R.S. Tranter, K. Moshammer, J.B. Randazzo, J.P.A. Lockhart, P.G. Fugazzi, T. Tao, A.L. Kastengren, Combust. Flame 181 (2017) 214-224.

[16] V. Gururajan, F.N. Egolfopoulos, K. Kohse-Höinghaus, Proc. Combust. Inst. 35 (2015) 821-829.

[17] A. Bhargava, P.R. Westmoreland, Combust. Flame 113 (1998) 333-347.

[18] J.M. Revet, D. Puechberty, M.J. Cottereau, Combust. Flame 33 (1978) 5-9.

[19] A.G. Shmakov, O.P. Korobeinichev, I.V. Rybitskaya, A.A. Chernov, D.A. Knyazkov, T.A. Bolshova, A.A.

Konnov, Combust. Flame 157 (2010) 556-565.

[20] V. Dias, J. Vandooren, Fuel 89 (2010) 2633-2639.

[21] V. Dias, J. Vandooren, H. Jeanmart, Proc. Combust. Inst. 35 (2015) 647-653.

[22] J. Vandooren, M.C. Branch, P.J. Van Tiggelen, Combust. Flame 90 (1992) 247-258.

[23] T.A. Cool, J. Wang, N. Hansen, P.R. Westmoreland, F.L. Dryer, Z. Zhao, A. Kazakov, T. Kasper, K. KohseHöinghaus, Proc. Combust. Inst. 31 (2007) 285-293.

[24] D.A. Knyazkov, A.G. Shmakov, O.P. Korobeinichev, Combust. Flame 151 (2007) 37-45.

[25] A.M. Dmitriev, D.A. Knyazkov, T.A. Bolshova, A.G. Tereshchenko, A.A. Paletsky, A.G. Shmakov, O.P. Korobeinichev, Combust. Flame 162 (2015) 3946-3959.

[26] D.A. Knyazkov, A.M. Dmitriev, T.A. Bolshova, V.M. Shvartsberg, A.G. Shmakov, O.P. Korobeinichev, Proc. Combust. Inst. 36 (2017) 1233-1240.

[27] O.P. Korobeinichev, M.B. Gonchikzhapov, A.A. Paletsky, A.G. Tereshchenko, A.G. Shmakov, I.E.

Gerasimov, D.A. Knyazkov, Proc. Combust. Inst. 36 (2017) 3279-3286.

[28] P. Oßwald, P. Hemberger, T. Bierkandt, E. Akyildiz, M. Köhler, A. Bodi, T. Gerber, T. Kasper, Rev. Sci. Instrum. 85 (2014) 025101.

[29] J. Krüger, G.A. Garcia, D. Felsmann, Kai Moshammer, A. Lackner, A. Brockhinke, L. Nahon, K. KohseHöinghaus, Phys. Chem. Chem. Phys. 16 (2014) 22791-22804.

[30] D. Krüger, P. Oßwald, M. Köhler, P. Hemberger, T. Bierkandt, Y. Karakaya, T. Kasper, Combust. Flame 191 (2018) 343-352.

[31] P. Hemberger, V.B.F. Custodis, A. Bodi, T. Gerber, J.A. van Bokhoven, Nat. Commun. 8 (2017) 15946.

[32] A. Bodi, P. Hemberger, T. Gerber, B. Sztaray, Rev. Sci. Instrum. 83 (2012) 083105.

[33] B. Sztaray, K. Voronova, K.G. Torma, K.J. Covert, A. Bodi, P. Hemberger, T. Gerber, D.L. Osborn, J. Chem. Phys. 147 (2017) 013944. 
[34] J. Pieper, S. Schmitt, C. Hemken, E. Davies, J. Wullenkord, A. Brockhinke, J. Krüger, A. Garcia Gustavo, L. Nahon, A. Lucassen, W. Eisfeld, K. Kohse-Höinghaus, Z. Phys. Chem. 232 (2018) 153.

[35] M. Kamphus, N.-N. Liu, B. Atakan, F. Qi, A. Mcllroy, Proc. Combust. Inst. 29 (2002) 2627-2633.

[36] Photonionization Cross Section Database (Version 2.0). http://flame.nsrl.ustc.edu.cn/database/. National Synchrotron Radiation Laboratory, Hefei, China. (2017) Compiled by J.Z. Yang and Combustion Team. Estimated data provided by Y.Y. Li, J.Z. Yang and Z.J. Cheng.

[37] P.M. Dehmer, Chem. Phys. Lett. 110 (1984).

[38] Chemical WorkBench ${ }^{\circledR} 4.0$, Kintech Laboratory, available online at http://www.kintechlab.com/products/chemical-workbench/.

[39] A. Lucassen, N. Labbe, P.R. Westmoreland, K. Kohse-Höinghaus, Combust. Flame 158 (2011) 1647-1666. [40] W. Becker, Vacuum 16 (1966) 625-632. 


\section{List of Figure captions}

Figure 8. Concept of the visualization of the molecular beam using the velocity map image.

Figure 9. Velocity map image of a molecular beam setup with marked beam signal and rethermalized signal.

Figure 10. Comparison between experimental $\mathrm{OH}$ mole fraction using the overall signal and ionization cross sections for the quantification, the experimental mole fraction using the partial equilibration and the USC II model predictions [2] in a butene doped $\mathrm{H}_{2}$ flame. The temperature profile is presented in blue.

Figure 11. Comparison of $\mathrm{OH}$ and $\mathrm{H}_{2} \mathrm{O}$ signal with focus on the molecular beam area (red) and the overall signal as well as the related BFs. For the illustration of the molecular beam a velocity map image is shown with molecular beam area marked in red.

Figure 12. (left)Overall and beam signal profiles of different radicals normalized to the maximum of the overall signal of the appropriate radical in the 1-butene doped flame and (right) the beam fractions for the same species.

Figure 13. Mole fraction profile of the $\mathrm{OH}$ radical using the beam signal for the quantification compared to the model predictions with the USC II [2] and the Aramco Mech 2.0 [3].

Figure 14. OH mole fraction profiles for all four fuel-doped flames compared to each other. 